
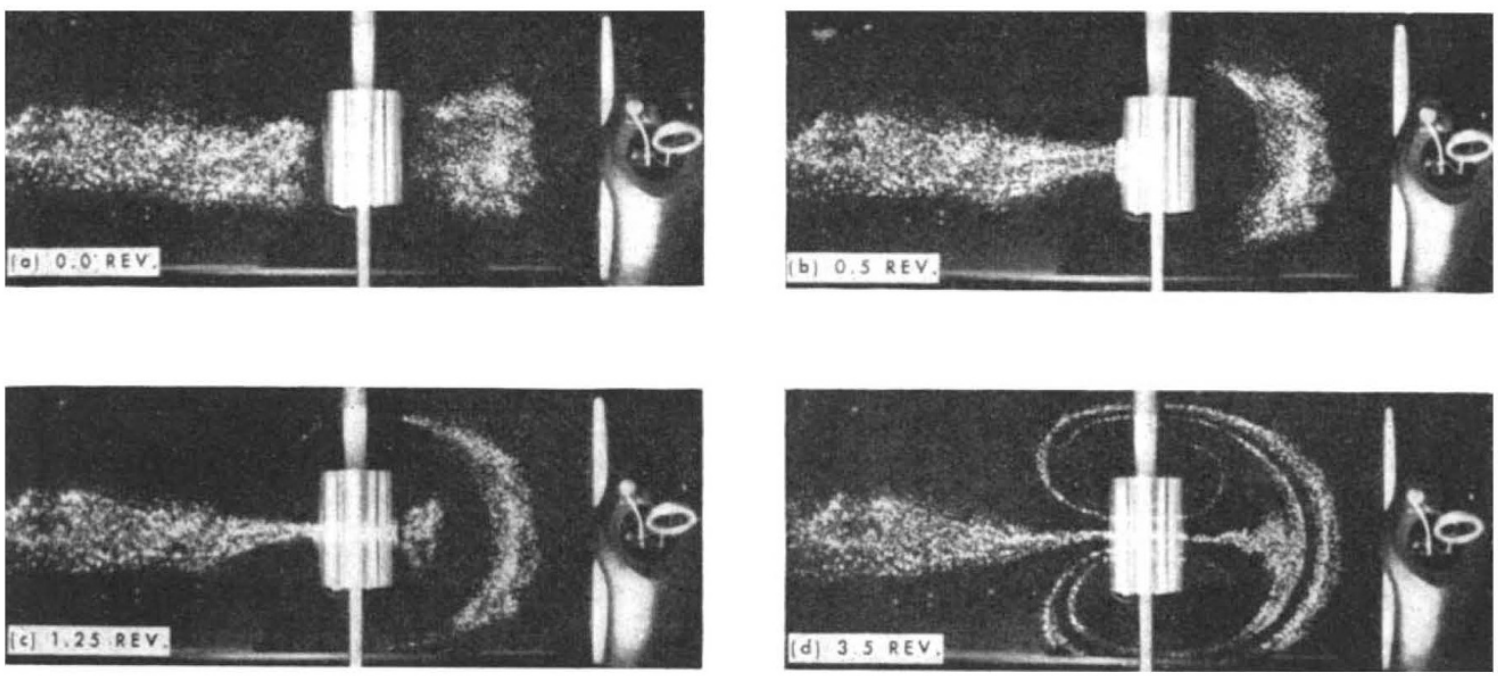

Fig. 1. Surface flow patterns produced by cylinder rotation in a monolayer of cetyl alcohol at 20 dynes $/ \mathrm{cm}$.

alcohol in its surface behaviour, except that it produces a considerably tighter cardioid pattern.

These observations suggest new methods for continuous transfer of films and for differentiating film-forming compounds. Moreover, the flow patterns shown with the cylinder system may greatly simplify problems in surface theology as well as provide a means for analysing problems in three-dimensional or bulk flow.

Herman E. Ries, jun. JOSEPH GABOR

Research and Development Department,

American Oil Company,

Whiting, Indiana.

Received October 24, 1966.

' Blodgett, K. B., and Langmuir, I., Phys. Rev., 51, 964 (1937).

"Ries, jun., H. E., and Kimball, W. A., J. Phys. Chem., 59, 94 (1955) and Proc. Second Intern. Cong. Surface Activity, 1,75 (Butterworths Scien-

${ }^{3}$ Ries, jun., H. E., and Walker, D. C., J. Coll. Sci., 16, 361 (1961).

* Walker, D. C., and Riss, jun., H. E., Nature, 203, 292 (1964).

\section{Hysteresis in the Flow through an Orifice}

DEckKER ${ }^{1}$ described a well defined hysteresis in the flow of air through square-edge circular orifices. The hysteresis was obtained with orifices of different diameters which all had length/diameter ratios of 0.5. He states "It is curious that this phenomenon had not been encountered earlier in the long history of investigation of the flow of compres sible fluids". This phenomenon of flow instability with the square-edge circular orifice has been reported in several previous investigations ${ }^{2-9}$ and there is now fairly wide agreement that the main factor influencing the value of the discharge coefficient is the extent to which the flow which separates from the orifice wall at the inlet edge reattaches itself to the wall before the outlet edge is reached ${ }^{10}$.

A discontinuity in the discharge coefficient/Reynolds number characteristic for an orifice with a length/ diameter ratio of 0.929 can be traced in Zucrow's ${ }^{2}$ experiments with benzol and again in orifices with various length/diameter ratios in the work of Koennecke ${ }^{3}$ using oil. An orifice tested in air by Grace and Lapple had a length/diamoter ratio of $1 \cdot 0$ for its upstream half followed by a diverging conical chamfer. The discharge coefficient/ Reynolds number characteristic showed that the discharge coefficient values were scattered between 0.61 and 0.84 over a small $(5: 1)$ flow range. Some of the secondary factors which could have caused this scatter are discussed, including minor pressure pulsations in the lines, vibration of the equipment, the surface condition of the orifice throat and the orifice approach conditions. Deckker's results show a somewhat similar, though smaller, scatter over the entire range of his investigation.

In a study of the flow stability of liquids in small square-edge cylindrical orifices Northup ${ }^{5}$ showed that the relation between mass flow and pressure drop sometimes consisted of two parallel curves and commented "Here the tendency for the descending flow to jump back to its high value, resulting in what might be called a hysteresis loop, is seen ...". Northup also tested a transparent orifice and showed that cavitation could be one of the causes of the instability of flow. Spikes and Pennington ${ }^{6}$ suggested that the effects of cavitation could cause a considerable change in the discharge coefficient for any length/diameter ratio greater than $0 \cdot 14$. They mention an apparent hysteresis in the unstable region and found that an orifice with a length/diameter ratio equal to 0.5 was the most unstable configuration of all. Nakayama experienced instability in some water tests using orifices with length/diameter ratios of 0.799 and 0.944 , when two different flow regimes were observed, but when air was used the instability did not occur.

Deckker's work is an interesting extension of these earlier investigations, but if stable flow is required the practical limitations of the square-edge cylindrical orifice have already been established.

Department of Mechanical and

$$
\text { J. C. MCVeIGH }
$$

Production Engineering,

Woolwich Polytechnic,

London.

1 Deckker, B. E. L., Nature, 209, 604 (1966).

${ }^{2}$ Zucrow, M. J., Purdue Univ., Eng. Exp. Station, 31 (1928).

${ }^{3}$ Koennecke, W., Forsch. Ing Wes., 9, 109 (1838).

- Grace, H. P., and Lapple C. E., Trans. Amer. Soc. Mtech. Eng., 73, 639 (1951).

${ }_{5}^{5}$ Nortbup, R. P., paper presented to Amer. Rocket Soe. (November 30, 1951).

'Spikes, K. H., and Pennington, G. A., Proc. Inst. Mech. Eng., London, 173. $661(1959)$.

7 Nakayama, Y., Bull. Jap. Soc. Mech. Eng., 4, 507 (1961).

${ }^{*}$ Battelle Memorial Inst. Wright Air Development Center, Tech. Kep., 56 344 (1957).

' Kastner, L. J., and McVeigh, J. C., Proc. Inst. Mech. Eng., London, 180, 331 (1965).

${ }^{10}$ Hall, G. W., Communication to Spikes and Pennington (ref, 6).

\section{Shear Elasticity in Organic Liquids}

Aт sufficiently high velocity gradients, shear elasticity ean show itself in a fluid by the development of stresses normal to the direction of shear. In 1960, Reiner ${ }^{1}$ claimed to have detected such normal stresses in toluene at velocity 